\title{
OVARIAN AGENESIS OR THE PTERYGIUM SYNDROME
}

\author{
BY \\ PER SKJELBRED \\ From the Paediatric Clinic of the University Hospital, Bergen
}

(RECEIVED FOR PUBLICATION SEPTEMBER 11, 1952)

Ovarian agenesis and the pterygium syndrome are terms recently coined. They represent two rare conditions infrequently reported in the literature. For an extensive survey of the historical development of these clinical pictures the reader is referred to papers by Wilkins and Fleischmann (1944b), Rossi and Caflisch (1951), Reiniger (1951) and Granrud (1952).

A short review reveals that Funke in 1902 gave the first account of deficient sexual development combined with pterygium colli (webbed neck). In 1938 Turner described the triad of infantilism, pterygium colli and cubitus valgus. In 1942 Varney, Kenyon and Koch and Albright, Smith and Fraser showed by means of hormone analysis of urine that similar cases of deficient sexual development were due to primary deficiency of the ovaries. Lastly Wilkins and Fleischmann (1944b) introduced the term "ovarian agenesis' based on findings at biopsy and necropsy. At the site of the ovaries were small, white ridges lacking germinal epithelium. In a few cases of this socalled sexual infantilism the ovaries have reached a later stage of foetal development, but never the stage of a normal newborn infant's ovaries.

Wilkins (1950) connects the following clinical features with ovarian agenesis: infantile breasts, labia, clitoris, vagina and uterus, as well as rudimentary or missing ovaries. Sexual hair is usually present, though in a moderate degree and often not till the age of 14 to 16 years. Growth in height is nearly always stunted, yet a case with normal height has been described. The maturation of the bones is approximately normal, as also is the development of the teeth. There is increased gonadotropin excretion in the urine but only after the age of 12 years, as urinary excretion of gonadotropin is very small before puberty. The excretion of 17-ketosteroids is normal or slightly reduced. To this picture may be added a series of conditions of varying frequency: pterygium colli, the Klippel-Feil syndrome, a lowered hairline of the neck, hypoplastic mandible, ocular abnormalities, deafness, coarctation of the aorta, hypertension, cubitus valgus, scoliosis and slight osteoporosis. The I.Q. is usually normal. Wilkins maintains that it is not known whether males present any condition corresponding to ovarian agenesis. In this connexion it may be noted that some cases of Turner's syndrome in the male have been recorded by Dorff, Appelman and Liveson (1948), Cunningham and Harley (1951) and Rossi and Caflisch (1951) among others. As to the incidence of the different symptoms, Wilkins and Fleischmann (1944b) point out that among 32 cases of ovarian agenesis 13 were associated with pterygium colli.

In short, ovarian agenesis is characterized by deficient sexual development combined with a varying series of anomalies. Most of the symptoms can be regarded as developmental defects and malformations. The aetiology is unknown. According to van Creveld and de Vaal (1949) ovarian agenesis has not been observed as a hereditary disease. On the other hand Kaijser (1949) has reported six cases in three of which the patients were closely related to each other, and Granrud (1952) reports a case of Turner's syndrome with familial traits of the disease.

Rossi (1945) introduced the pterygium syndrome, and in 1951 Rossi and Caflisch analysed it on the basis of 177 cases collected from the literature as well as 20 of their own cases. Their analysis comprised such conditions as the status BonnevieUllrich, in addition to pterygium specially characterized by lymphangiectatic oedema, muscle aplasia, disturbance of the cranial nerves, retardation of growth, skeletal anomalies, etc.; Turner's syndrome; Nielsen's dystrophia brevicollis congenita, particularly recognized by the Klippel-Feil syndrome, pterygium colli and anomalies of the hairline of the neck; and lastly pterygo-arthromyodysplasia congenita: pterygium of the limbs, muscle aplasias and defects of the joints, arthrogryposis. Pterygium was found in all 197 cases, the neck being involved in 135 of them. Sixty-eight cases showed infantilism of the Turner type, among which 12 were distinct, and there were three mild cases in the male. Of the 197 cases, the sex was known of 115 females and 67 males, and was not stated in 15 cases. Other manifestations of the syndrome found in varying 
degree were stunted growth, anomalies of the spine, cubitus valgus, hypoplastic mandible, a characteristic physiognomy described as bec de lièvre or greule de loup (hare beak or wolf jaw), congenital heart defects (usually coarctation of the aorta or defective interventricular septum), malformations of the hands and feet, lymphangiectatic oedema, muscle aplasias, and disturbances of the cranial nerves or possibly of the muscles supplied by them.

It will be seen that most of these features are the same as those connected with ovarian agenesis. We note particularly that in one-third of the cases there were signs of infantilism and hypogonadism. It seems that the occurrence of pterygium to a certain extent is familial. In 27 cases Rossi and Caflisch found hereditary traits. The same authors collected 120 cases of primary hypogenesis or agenesis of the gonads from the literature, pterygium being present in half of them.

It may well be asked whether ovarian agenesis and the pterygium syndrome represent two different conditions. Primary hypogonadism is probably a more proper term than ovarian agenesis, because complete agenesis of the ovaries is not always present, and because Turner's syndrome is reported in the male. From one-third to a half of the recorded cases of primary hypogonadism present pterygium. Fully one-third of the recorded cases of the pterygium syndrome show primary hypogonadism. Is such a frequent coincidence of two such rare conditions merely accidental? One should rather assume that they represent two different manifestations of the same syndrome of defective development and malformations. In both ovarian agenesis and the pterygium syndrome the aetiological factor has evidently operated at the organo-genetic stage of development. The injurious factor or factors will not always cause clinically uniform results, as both the mentioned syndromes include a series of variable features. There should be no reason to stress the pterygium syndrome as a more essential symptom than the hypogonadism or vice versa. A more comprehensive term is needed.

The aetiology and pathogenesis of this condition are unknown. Both the pterygium syndrome and ovarian agenesis may appear hereditary. Ullrich (1938) has tried to find conformity between pterygium colli and the myelencephalic blebs of the neck of Bagg-Little mice raised by inbreeding mice exposed to $x$-rays and showing a series of malformations. According to Bonnevie (see Reiniger, 1951), these blebs are formed early in foetal life owing to increased pressure of the liquor. They extend to the periphery, the damage done by them depending on their physical action. Similar blebs in the human foetus have been described (Reiniger, 1951), but it is difficult to apply Bonnevie's theory to more than a few of all the manifestations of this syndrome (Glanzmann, 1951; Launay, Matet and Colbert, 1951).

\section{Treatment}

The most important feature of the syndrome requiring treatment is the deficient sexual development. Here substitution therapy with gonad hormones is rational. According to Wilkins (1950) females should be given oestrogenic substance, usually stilboestrol, in doses from 0.5 to $5 \mathrm{mg}$. daily, usually $1 \mathrm{mg}$., for several months. When the genitals have reached the stage of adolescent development, or endometrial bleeding occurs, cyclic treatment is instituted. For two weeks stilboestrol alone is given, then for one week stilboestrol plus progesterone, 10-30 mg. daily, in order to simulate normal cycles, with no drugs during the fourth and last week of the cycle. Bleeding usually occurs two to three days after treatment is stopped. This treatment must be permanent. Of course fertility cannot be achieved.

A case has been recorded where this treatment was supplemented by testosterone on the assumption that if the suprarenal cortex is partially defective, shown by the absence of sexual hair and reduced excretion of 17-ketosteroids, the provision of androgen may be indicated. The assumption was justified by the development of sexual hair and increased growth in height, a result not achieved by stilboestrol treatment (van Creveld and de Vaal, 1949).

Among the other manifestations of the syndrome, pterygium colli may be treated by cosmetic operation. The hypertension requires a protective regime.

The expectation of life of these patients has not been calculated statistically. It may be impaired by hypertension or heart disease.

These reflections are due to a characteristic case of the pterygium syndrome, or ovarian agenesis if that term seems more convenient, treated at the Paediatric Clinic, Bergen.

\section{Case Report}

A girl, H.D. (1090/51), was barely 16 years old when first seen on June 28,1951 . Her paternal grandmother was of small stature, as were several of her father's siblings, without other striking external characteristics: no cases of malformation in the family were known. Her mother was well during the pregnancy, she had suffered from no infection, and had not been exposed to $\mathrm{x}$-rays. The patient's weight was $4,000 \mathrm{~g}$. and length $50 \mathrm{~cm}$. There was nothing noteworthy about the physical or mental development during infancy and early childhood. She acquired the ordinary children's diseases before she was 7 years old, and had also suffered from 


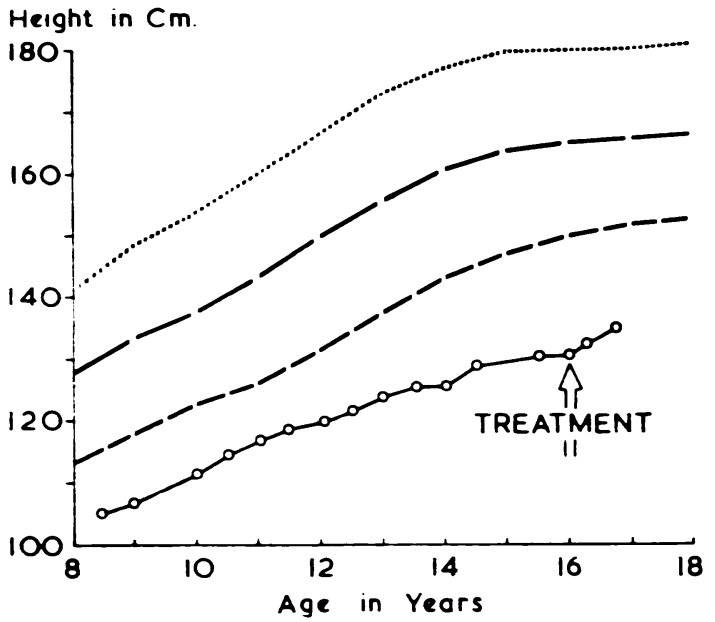

FIG 1.-The patient's height-curve (o__o_ 0 ) in relation to the normal figures (according to Broman, Dahlberg and Lichtenstein, $1941)$.

pneumonia and otitis media. Otherwise she was in good health. When 10 or 11 years old she developed several small, brown naevi on the face, trunk and limbs. She attended school at the ordinary age, meeting its requirements without difficulty. Her temperament had been normal. When she first went to school it was noticed that she was shorter than her companions of the same age, but it was not until five or six years later, about the age of 13 , that she was suspected of suffering from a more serious disturbance. The secondary sexual signs did not develop, the menarche failed. Her height and weight had been measured regularly since her second year in school. Fig. 1 shows her height in relation to the average height for normal girls of her age. On the whole her height kept about $20 \%$ below the average. She had not suffered from headache, visual disturbances, dyspnoea or oedema, and had received no treatment before admission to the clinic.

On admission she was found to be of short and stocky build, well proportioned. Her height was $130 \mathrm{~cm}$. (average for her age $164.5 \mathrm{~cm}$.); her weight was 37.5 $\mathrm{kg}$. (average for her height $27 \cdot 5$ kg.). Her face was peculiar (Fig. 2) as she had slight internal epicanthus, a short and stumpy nose, a hypoplastic mandible, and an upper lip so short that it gave the mouth an appearance suggestive of a rodent's. She had 24 teeth, the 12-year molars being missing, and a high palate. Respiration was untroubled. There was no cyanosis. Blood pressure in the arms was about $195 / 110 \mathrm{~mm}$. $\mathrm{Hg}$, in the legs about $255 / 210$. Subsequent repeated recordings were about $180 / 115$ and $250 / 170$ respectively. On the forehead were dilated veins. There was no oedema. The skin presented several small, brown naevi, but appeared otherwise normal. The hair of the head was dry and thick, with a lowered hairline on the neck. The neck was short, with bilateral pterygium colli of moderate degree. The ears appeared normal. The circumference of the head was $55 \mathrm{~cm}$. The thyroid gland was not enlarged. The thorax was arched and well developed. The breasts were infantile. The second cardiac sound over the base of the heart was accentuated, but a physical examination of the heart proved negative otherwise. The lungs and abdomen showed no abnormality. The external genitals were infantile, and there was no sexual hair. The limbs were normal except for a moderate degree of cubitus valgus. No neurological abnormalities were perceived and mentally the girl was normal. Digital exploration per rectum by a gynaecologist revealed a small uterus, and no ovaries could be palpated. Examination by an ophthalmologist showed rather ill-defined nasal borders of the optic discs. At the centre of the fundus oculi the vessels were tortuous, and the veins to some extent dilated. There was no arteriovenous compression, no oedema of the retina, haemorrhages, or signs of degeneration.

Electrocardiographic examination showed left axis deviation. Radiologically the heart showed an enlarged left ventricle and a rather wide aortic arch.

Findings on intravenous urography were normal.

$\mathrm{X}$-ray examination of the bones revealed centres of ossification and epiphyseal lines within normal variations. The sella turcica was normal. The impressiones digitatae were not increased. The intervertebral spaces were somewhat narrowed. Of the lower thoracic vertebrae, the upper and lower surfaces were rather uneven. The lower metaphysis of the right femur showed cystic osteoporosis of the size of an almond.

Laboratory Findings. The ordinary urine tests were
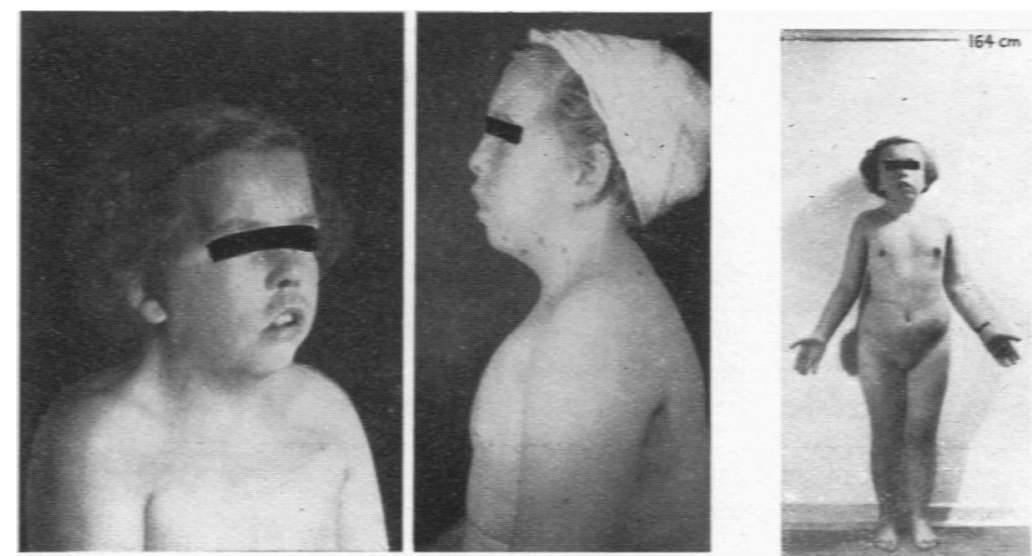

F1G. 2.-Photographs of H.D. when about 16 years old. Note the pterygium colli, the lowered hairline of the neck, the curious physiognomy (bec de lievre), numerous naevi, the stocky build with proportioned stunted growth and cubitus valgus and the absence of sexual hair. (The photograph on the right is taken after onset of treatment. thus pigmented areola.) 
negative. Normal figures were also found for dilution and concentration of the urine, diuresis, blood urea level, carbon dioxide concentration in plasma, urea-clearance and creatinin excretion on the tolerance test. The blood picture was normal, as were the figures for serum sodium, potassium, chlorides, calcium, phosphates, alkaline phosphatase and cholesterol. Basal metabolism was normal. The blood sugar curves presented a normal appearance on glucose tolerance and insulin tolerance tests. Tuberculin and Meinicke reactions were negative. Hormone analysis of the urine gave follicle-stimulating hormone*, about $111 \mathrm{~m} . u$./litre; luteinizing hormone, $33 \mathrm{~m} . \mathrm{u}$./litre; oestrogens, $17 \mathrm{~m} . \mathrm{u} . /$ litre. The excretion of 17 -ketosteroids is recorded in Fig. 3.

Treatment. From August 26, 1951, stilboestrol ('stilbofollin nyco') was given by mouth, $0.5 \mathrm{mg}$. daily for three days, and later $1 \mathrm{mg}$. daily. After seven weeks of treatment the first vaginal bleeding occurred, and stilboestrol was withdrawn. The bleeding lasted five or six days, and stilboestrol was given again after one week. Bleeding reappeared when the drug was withdrawn after another five weeks of treatment. Since then bleeding, lasting five to six days, has begun regularly the day after stilboestrol is withdrawn. Since December 11, 1951, cyclic treatment has been given, with stilboestrol for three

\footnotetext{
* Follicle-stimulating and luteinizing hormones and oestrogen were determined at Nyegaard \& Co.'s biological laboratory, Oslo. Normal figures for follicle-stimulating hormone are about $33 \mathrm{~m} . u$. 1 . For a short time during puberty the excretion may be increased to between $33 \mathrm{~m} . \mathrm{u} . / 1$ and $110 \mathrm{~m} . u$. $/ 1$. Luteinizing hormone is not excreted in the urine under normal conditions. Oestrogen in childhood, during the climacteric in women and in men is below 17 m.u. 1 . In normally menstruating women it is from 17 m.u./1 to $167 \mathrm{~m} . \mathrm{u} / 1$ determined by the Allen-Doisy method. 17-Ketosteroids were determined by K.Fr. Stoa, of the biochemical laboratory, Haukeland Hospital, Bergen, by Hamburger's method. The normal values for a girl of our patient's age range from $2 \cdot 4$ to $14 \cdot 2 \mathrm{mg}$. 24 hours, with $8.6 \mathrm{mg}$. $24 \mathrm{hr}$. as the mean.
}

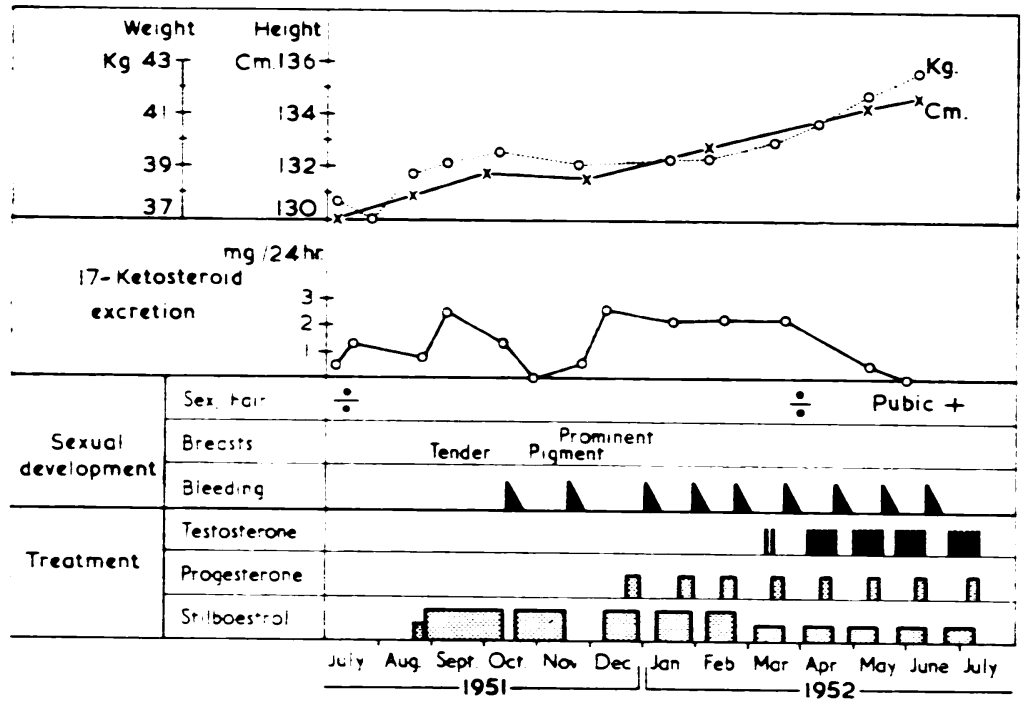

FiG. 3.-The results of hormonal treatment of the patient. weeks and no treatment during the fourth week. From March 7, 1952, the dosage was reduced to $0.5 \mathrm{mg}$. daily, with bleeding occurring as regularly as before the reduction in dosage.

On December 24, 1951, progesterone was added to the treatment, in the forms of anhydroprogesterone lingualettes, ('progestin $\mathrm{P}$ ', Organon) $10 \mathrm{mg}$. daily, in the third week of the cycles. This has produced no change in the clinical picture.

A few days after the beginning of treatment with stilboestrol the breasts were slightly tender. After six weeks of treatment the areola showed distinct pigmentation, the breasts were slightly enlarged, and the nipples prominent. Later the mammae enlarged but little.

During treatment there was no growth of sexual hair. Since March 17, 1952, testosterone propionate has been added ('testin nyco', kindly placed at our disposal by Nyegaard and Co., Oslo), $25 \mathrm{mg}$. intramuscularly twice weekly for the first three weeks of the cycles. Two months later pubic hair began to grow.

The results of the treatment are shown in Fig. 3, with the height and weight measurements and the 17-ketosteroid excretion. The height shows improvement during treatment (cf. Fig. 1). The 17-ketosteroid excretion has kept distinctly below normal values, and, most noteworthy, has fallen to zero after treatment with testosterone.

The blood pressure has remained unchanged during treatment. The centres of ossification and epiphyseal lines have developed normally as judged by $x$-ray controls. The patient has complained of no discomfort during treatment.

This case presents typical features of the pterygium syndrome as well as ovarian agenesis. An exploratory laparotomy might be desirable, but is not necessary to confirm the diagnosis. It may be of interest to deal with the following points in some detail.

With regard to the sex characteristics, it is held that the development of the breasts, labia minora, vagina and uterus is stimulated by oestrogen, the mammary glands by progesterone, the labia majora and clitoris by androgen, whereas the growth of sexual hair is chiefly regulated by androgen, possibly by an interplay of oestrogen and androgen (Wilkins, 1950). Engstrom and Munson (1951) maintain that the factors influencing the growth of sexual hair are complex and not fully understood. In ovarian agenesis there is sometimes reduced excretion of 17-ketosteroids, as well as absence of sexual hair. This 
may indicate a reduced production of androgen. Finding no failure of the electrolyte balance or glucose metabolism, we are possibly dealing with a partial failure of the adrenal cortex. A case of ovarian agenesis has been recorded in which postmortem examination revealed a hypoplastic adrenal cortex (Atria, Saur and Donoso, 1948), and in which sexual hair was absent. Thus androgen therapy in ovarian agenesis should be rational.

In our case the excretion of 17-ketosteroids was reduced during treatment with testosterone. This may have been accidental, or testosterone may have suppressed the androgen function of the adrenals directly or via the hypophysis. At any rate it is noteworthy that a weekly supply of $50 \mathrm{mg}$. testosterone intramuscularly was followed by a reduction of the 17-ketosteroid excretion to $0 \mathrm{mg}$. $/ 24$ hours.

Why is growth in height stunted in ovarian agenesis? It is unlikely to depend on hypofunction of the hypophysis or the thyroid gland. Inhibition of growth due to some other known cause (cerebral, cardiac, renal, etc.) may also be dismissed. Ovarian deficiency has been discussed as a possible cause. With increased oestrogen production, as in granulosa cell tumour, growth in height may be increased (Warkany, 1950). On the other hand castration before puberty may lead to increased growth. This excludes the agenetic ovaries as the origin of the stunted growth. It is found that androgens may stimulate growth, particularly during the years of puberty. As already pointed out, ovarian agenesis is often associated with signs of reduced androgen production. If this reduction should be responsible for the diminished growth, the stunting is unlikely to appear before puberty. It is not so. At the age of 8 years our patient was $20 \%$ below average in height. It is commonly supposed that this inhibition of growth depends on genetic factors, being a developmental anomaly in line with other manifestations of the syndrome (Wilkins, 1950).

Several authors apply the term 'sexual infantilism' to the clinical picture presented by ovarian agenesis (Wilkins and Fleischmann, 1944a; van Creveld and de Vaal, 1949; Kaijser, 1949; Wilkins, 1950; Granrud, 1952). It has not been possible to find any definition of this term. Infantilism generally indicates an inhibition of the whole organism in an infantile phase and may be due to deficiency of a special organic system, infantilism being further classified according to its cerebral, cardiac, renal or other origin respectively. By analogy sexual infantilism should imply stunted growth due to hypofunction of the gonads. From what has already been said it is evident that the term sexual infantilism does not cover the conditions, as far as they are known, and should not be applied.
Gonad hypofunction can hardly be responsible for more than the sexual underdevelopment.

Hypertension is no rare finding in ovarian agenesis. Among 15 cases hypertension was found in 10 (Wilkins and Fleischmann, 1944b). In these cases the upper limit of the systolic pressure was about $150 \mathrm{~mm}$. $\mathrm{Hg}$, with a diastolic pressure about $110 \mathrm{~mm}$. In our case the blood pressure was remarkably high. It has not been possible to discover definite aetiological factors accounting for hypertension, cases with coarctation of the aorta excluded. No renal or adrenal cause has been demonstrated.

In ovarian agenesis fairly extensive osteoporosis is usually found. The cystic form presented by our case has also been reported before (Wilkins and Fleischmann, 1944b). The development of the teeth is said to proceed normally. In our case it was somewhat delayed.

We do not know to what extent, if any, there is a connexion between the multiple naevi observed in our case and this syndrome of developmental defects. Haney (1952) has lately reported a case of ovarian agenesis with numerous moles on the skin.

When primary hypogonadism takes the monosymptomatic form with only deficient sexual development its recognition before puberty may be very difficult, and the diagnosis will apparently not be supported by hormone analysis. However, a case has recently been reported in which increased gonadotropin excretion was observed in a girl barely 3 years old suffering from ovarian agenesis (Silver, 1951).

\section{Summary}

The history and symptomatology of ovarian agenesis and the pterygium syndrome are surveyed. Their aetiology and pathogenesis are discussed. In view of the features which these two syndromes have plainly in common, it is argued that they should be regarded as different manifestations of the same syndrome.

Treatment and prognosis are reviewed.

A report is given of a typical case, treated with stilboestrol, progesterone and testosterone. Some of its symptoms are discussed. The term 'sexual infantilism' is criticized.

I should like to thank Professor Alfred Sundal for his help and encouragement in preparing this paper.

\section{REFERENCES}

Albright. F.. Smith. P. H. and Frase-, R. (1942). Amer. J. med. Sci., 204. 625

Atria, A., Saur, R. and Donoso, S. (1948). J. clin. Endocr.. 8, 397 (ref. van Creveld and de Vaal).

Broman. A., Dahlberg. G. and Lichtenstein. A. (1941). Vord. Larebog i Padiat., 1. 7. Munksgaard, Copenhagen.

Creveld. S. van and Vaal. O. M. de (1949). Acta paediat.. Lppsala, 37, 474. 
Cunningham, G. C. and Harley, J. F. (1951). J. Pediat, 38, 738.

Dorf, G. B., Appelman, D. H. and Liveson, A. (1948). Arch. Pediat., 65,555 .

Engstrom, W. W. and Munson, P. L. (1951). Amer. J. Dis. Child.,

Funke (1902). Dtsch. Z. Chir., 63. 162.

Glanzmann, E. (1951). Ann. paediat., Basel, 176, 356.

Granrud, H. (1952). Nord. Med., 47, 314.

Haney, C. A. (1952). J. Pediat., 40, 651 .

Kaiiser, K. (1949). Acta endocr. Kbh., 3, 351.

Launay, C., Matet, Y. and Colbert, J. (1951). Arch. frans. Pediat. 8. 626 .

Reiniger, M. (1951). Ann. paediat., Basel, 176, 32.
Rossi, E (1945) Helv paediat Acta 1,134

Silver, and Caflisch, A. (1951). Ibid., 6, 119

Silver, H. K. (1951). Pediatrics, 8, 368.

Turner, H. H. (1938). Endocrind., 23, 566.

Ullrich, O. (1938). Klin. Wschr., 17, 185.

Varney, R. F., Kenyon, A. T. and Koch, F. C. (1942). J. clin. Endocr., 2. 137

Warkany, J. (1950). In Mitchell-Nekson's Textbook of Pediatrics, ed. W. E. Neison, 5th ed., p. 1418. Saunders, Philadelphia.

Wilkins. L. (1950). The Diagmosis and Treatment of Endocrine Dis orders in Childhood and Adolescence. Springfield Illinois. and Fleischmann. W. (1944a). J. clin. Endocr., 4, 306. 